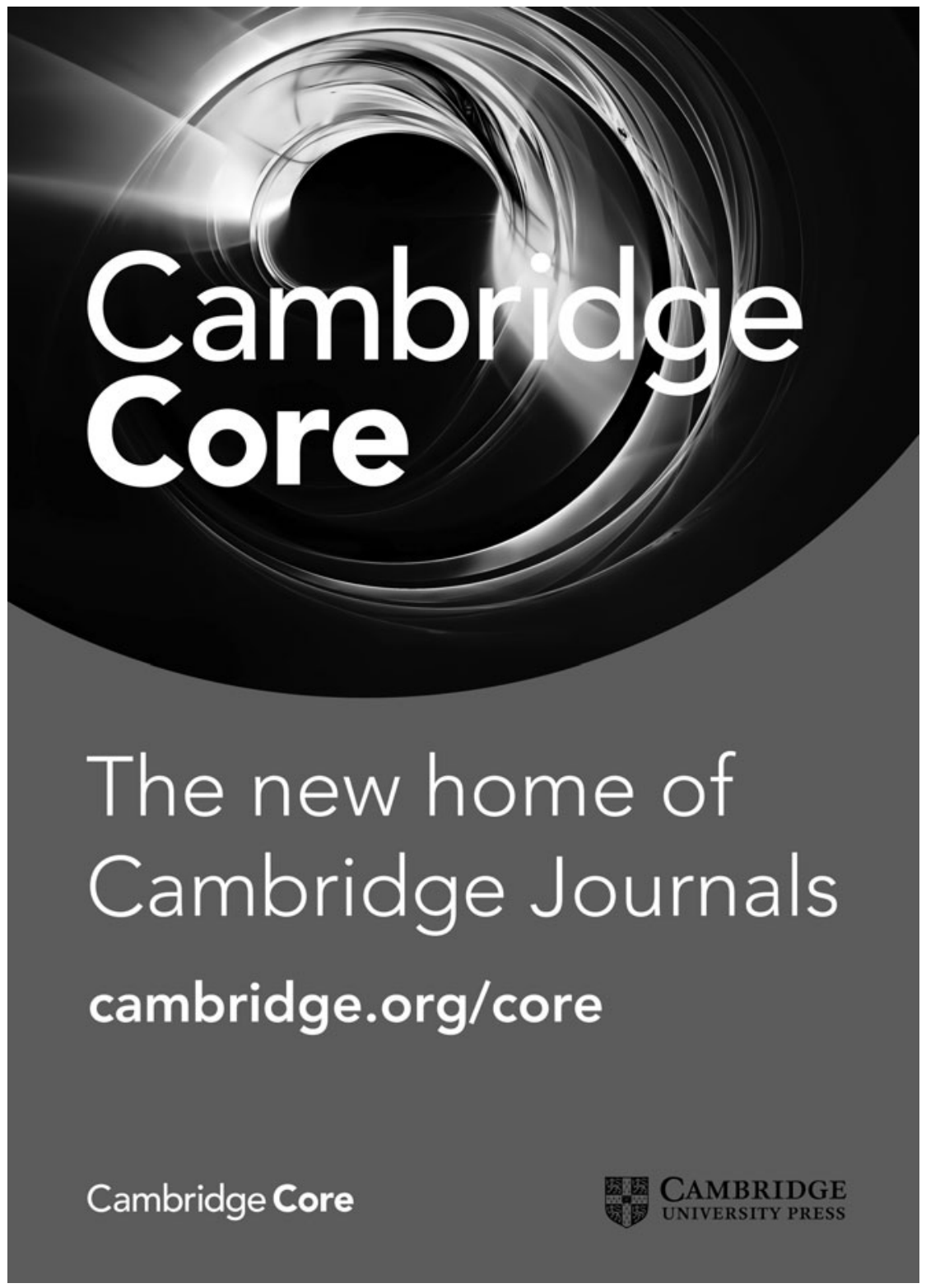




\section{THE LANGUAGE OF}

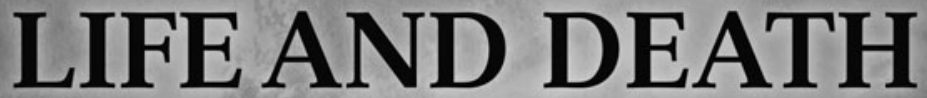

The Transformation of Experience in Oral Narrative

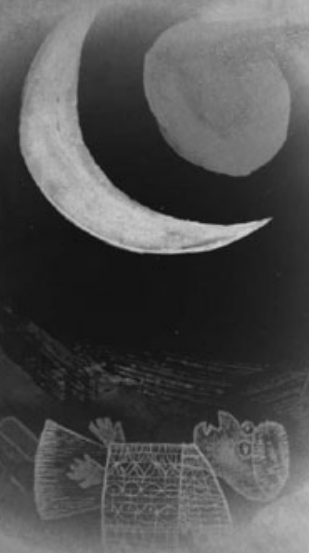

Labov extends his widely used framework for narrative analysis to matters of greatest human concern: accounts of the danger of death, violence, premonitions, and large-scale community conflicts. This book provides a rich range of narratives that grip the reader's attention together with an analysis of how it is done.

Not only relevant to students of narratology, discourse and sociolinguistics, this book will be rewarding reading for anyone interested in the human condition.

July $2013 \cdot \mathrm{PB} \mid$ \&17.99 $\cdot$ HB I $£ 55.00$

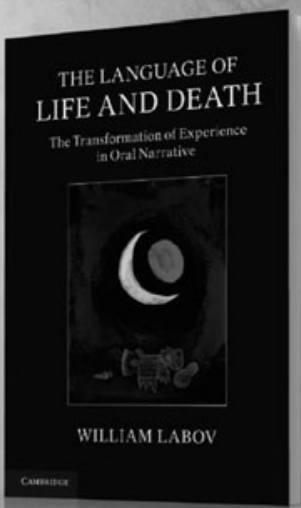

\section{www.cambridge.org/labov}




\section{Language Variation and Change}

\begin{abstract}
NOTES FOR CO
Language Variation and Change publishes original
research reports that are based on data of language production, either oral or written, from contemporary or historical sources. Articles that synthesize or reanalyze a number of research findings on substantive issues will also be considered. Conforming to scientific methodology, the reported findings should be fully replicable from the information provided.
\end{abstract}

Contributions may be submitted from all countries. The usual language of publication is English. All submissions should be submitted electronically, and by postal mail. Please send both a Word and PDF version to lvcjournal@psu.edu, and one hard copy to:

Rena Torres Cacoullos

Department of Spanish, Italian and Portuguese Pennsylvania State University

231 Burrowes Building

University Park, PA 16802

Submission of an article is taken to imply that it has not been previously published or is not being considered for publication elsewhere. If an author is publishing a related article, this fact should be stated.

Copyright. Contributors of accepted articles will be asked to assign their copyrights, on certain conditions, to Cambridge University Press, to help protect their material, particularly in the U.S.A.

\section{Manuscript Preparation and Style}

Manuscripts should generally not exceed 40 doublespaced pages. The entire manuscript-including abstract, endnotes, references, and tables-must be double-spaced and numbered consecutively. For the initial submission, tables and figures may be included in the running text. The article should be arranged as follows:

Title Page (page 1). The title page includes (a) full title, (b) names and affiliations of all authors, (c) mailing address, phone number, and email address of the lead author, (d) short title of less than 50 characters. All pages following the title page should show the short title plus page number in the upper right corner.

Abstract (page 2). Include the full title and the abstract. Abstracts should not exceed 150 words.

Acknowledgments (page 2). Place below the abstract. Use this section to indicate any grant support, substantial assistance in the preparation of the article, or any other author notes.

Text (page 3). Use a 5-character paragraph indent. Do not hyphenate words or justify the right margin. Glosses should be placed within single quotation marks.

References are to be made in the text (not in the endnotes) by giving in parentheses the name of the author, year of publication, and, where relevant, the page(s) referred to: (Vincent, 1982:90-91). If the author's name is part of the text, the following form should be used: "Vincent (1982) listed several. ..." For multi-authored works, only the first citation should list all authors: (Weinreich, Labov, \& Herzog, 1968). In subsequent citations, only the first name should be given, followed by "et al.": (Weinreich et al., 1968). Separate works referred to in the same parentheses should be listed in alphabetical order; those by the same author should be separated by commas and those by different authors by semi-colons: (López Morales, 1981; Vincent, 1981, 1982). Initials should be used (before the author's name) only when it is necessary to distinguish between two or more authors with the same surname referred to in the same article.

All works referred to in the text must be listed in the reference section in alphabetical order.

Examples of references (note the use of punctuation marks within references)

Cedergren, Henrietta J. (1973). Interplay of social and linguistic factors in Panama. Doctoral dissertation, Cornell University.

López Morales, Humberto. (1981). Velarization of $/ \mathrm{n} /$ in Puerto Rican Spanish. In D. Sankoff \& H. J. Cedergren (eds.), Variation omnibus. Edmonton: Linguistic Research. 105-113.

Tagliamonte, Sali, \& Poplack, Shana. (1980). How Black English Past got to the present: Evidence from Samaná. Language in Society 17:513-533.

Vincent, Diane. (1982). Pressions et impressions sur les sacres au Québec. Montréal: Office de la langue française.

Endnotes may be used when more than a simple citation is required. Notes should be numbered consecutively throughout the text and typed together on a separate page preceding the reference section.

Tables. Tables must appear as a unit following the reference section. Each table should be typed on a separate sheet, numbered consecutively with an Arabic numeral, and identified by a short title. All tables must be cited in the text.

Figures. All figures should be numbered consecutively with Arabic numbers.

Numbered figures and their descriptive legends must appear as a unit following the tables in the manuscript.

All figures should be supplied as electronic files: Please supply diagrams and other line drawings as $1200 \mathrm{dpi}$ TIFF or EPS files. Please supply photographs as $300 \mathrm{dpi}$ (or higher) TIFF files. All figures must be cited in the text.

Appendices. Lengthy and technical appendices may optionally appear in the online version only.

\section{Proofs}

First proofs will be sent to the lead author, who will be expected to correct and return them to Cambridge, by email, within 48 hours of receipt. 


\section{LANGUAGE VARIATIONANDGHANGE}

VOLUME 29, NUMBER 12017

\section{CONTENTS}

\section{JOSEF FRUEHWALD}

Generations, lifespans, and the zeitgeist

ERIK SGHLEEF, NIGHOLAS FLYNN AND WILLIAM BARRAS

Regional diversity in social perceptions of (ing)

\section{EARL K. BROWN AND MATTHEW G. ALBA}

The role of contextual frequency in the articulation of initial /f/ in Modern

Spanish: The same effect as in the reduction of Latin / $/ /$ ?

\section{THOMAS KETTIG AND BODO WINTER}

Producing and perceiving the Canadian Vowel Shift: Evidence from a Montreal community

\section{AARON J. DINKIN AND ROBIN DODSWORTH}

Gradience, allophony, and chain shifts 